\title{
Circulating tumor cells detected only after surgery for non-small cell lung cancer: is it a predictor of recurrence?
}

\author{
Noriyoshi Sawabata ${ }^{1,2}$, Toshitaka Nakamura ${ }^{1}$, Takeshi Kawaguchi ${ }^{2}$, Takashi Watanabe ${ }^{2}$, \\ Noriko Sageshima Ouji ${ }^{3}$, Toshihiro Ito ${ }^{3}$, Shigeki Taniguchi ${ }^{2}$ \\ ${ }^{1}$ Respiratory Disease Center, Hoshigaoka Medical Center, Hirakata City, Osaka, Japan; ${ }^{2}$ Department of Thoracic and Cardio-Vascular Surgery, \\ ${ }^{3}$ Department of Immunology, Nara Medical University, Shijo-cho Kashihara City, Nara, Japan \\ Contributions: (I) Conception and design: N Sawabata; (II) Administrative support: T Nakamura, T Kawaguchi; (III) Provision of study materials or \\ patients: T Nakamura, T Kawaguchi; (IV) Collection and assembly of data: NS Ouji, T Ito; (V) Data analysis and interpretation: N Sawabata, T \\ Nakamura; (VI) Manuscript writing: All authors; (VII) Final approval of manuscript: All authors. \\ Correspondence to: Noriyoshi Sawabata, MD, PhD, Professor. Department of Thoracic and Cardio-Vascular Surgery, Nara Medical University, 840 \\ Shijo-cho Kashihara, Nara 634-8511, Japan. Email: nsawabata@hotmail.com.
}

\begin{abstract}
Background: Surgical manipulation of a tumor can lead to shedding of tumor cells that can enter the circulation and lead to metastasis. The present study evaluated the clinical relevance of circulating tumor cells (CTCs) that were identified immediately after non-small cell lung cancer resection in patients without preoperative CTCs, and whether postoperative CTC detection was associated with recurrence.

Methods: Immediate preoperative testing for CTCs was performed for 147 patients with pulmonary nodules. This study included 81 lung cancer patients (55.1\%) with negative preoperative results for CTCs and who completed postoperative testing for CTCs. The clinical relevance of postoperative CTC detection was evaluated based on the clinicopathological characteristics and recurrence patterns.

Results: Among the eligible patients, the postoperative CTC results were none detected in 58 patients (71.6\%, "Group N"), only a single CTC detected in 6 patients (7.4\%, "Group S"), and CTC clusters detected in 17 patients $(21.0 \%$, "Group C"). The presence of postoperative CTCs was associated with tumor vessel invasion, lymph duct invasion, and pleural invasion. Distant metastasis was very common in cases with postoperatively detected CTC clusters. The 2-year recurrence-free survival rates were $94.6 \%$ for Group N, $62.5 \%$ for Group S, and $52.9 \%$ for Group $\mathrm{C}(\mathrm{P}<0.01)$. Multivariate analysis revealed that recurrence was independently related to the postoperative detection of single CTCs and CTC clusters.

Conclusions: In cases without preoperative CTCs, we postoperatively detected CTCs and the postoperative CTC results were an independent predictor of recurrence.
\end{abstract}

Keywords: Lung cancer; surgery; circulating tumor cell (CTC); recurrence

Submitted Apr 10, 2020. Accepted for publication Aug 05, 2020.

doi: $10.21037 /$ jtd-20-1636

View this article at: http://dx.doi.org/10.21037/jtd-20-1636

\section{Introduction}

Peripheral circulating tumor cells (CTCs) can generate metastatic lesions (1), and it is important to control CTC shedding during surgical procedures, which can be achieved using the "no-touch isolation technique" (NTIT). A representative example of the NTIT surgery involves mesenteric vascular ligation for colorectal cancer, which
Turnbull et al. reported was a superior treatment strategy in 1967 (2). Since that time, various reports have addressed the NTIT, including a recent prospective randomized trial (3). Thus, if CTCs are released during surgery, and if these cells predict metastasis and recurrence, it would be critical to determine whether CTCs are truly controlled during surgery. Although several reported cases have revealed that perioperative CTC detection predicts a poor prognosis 


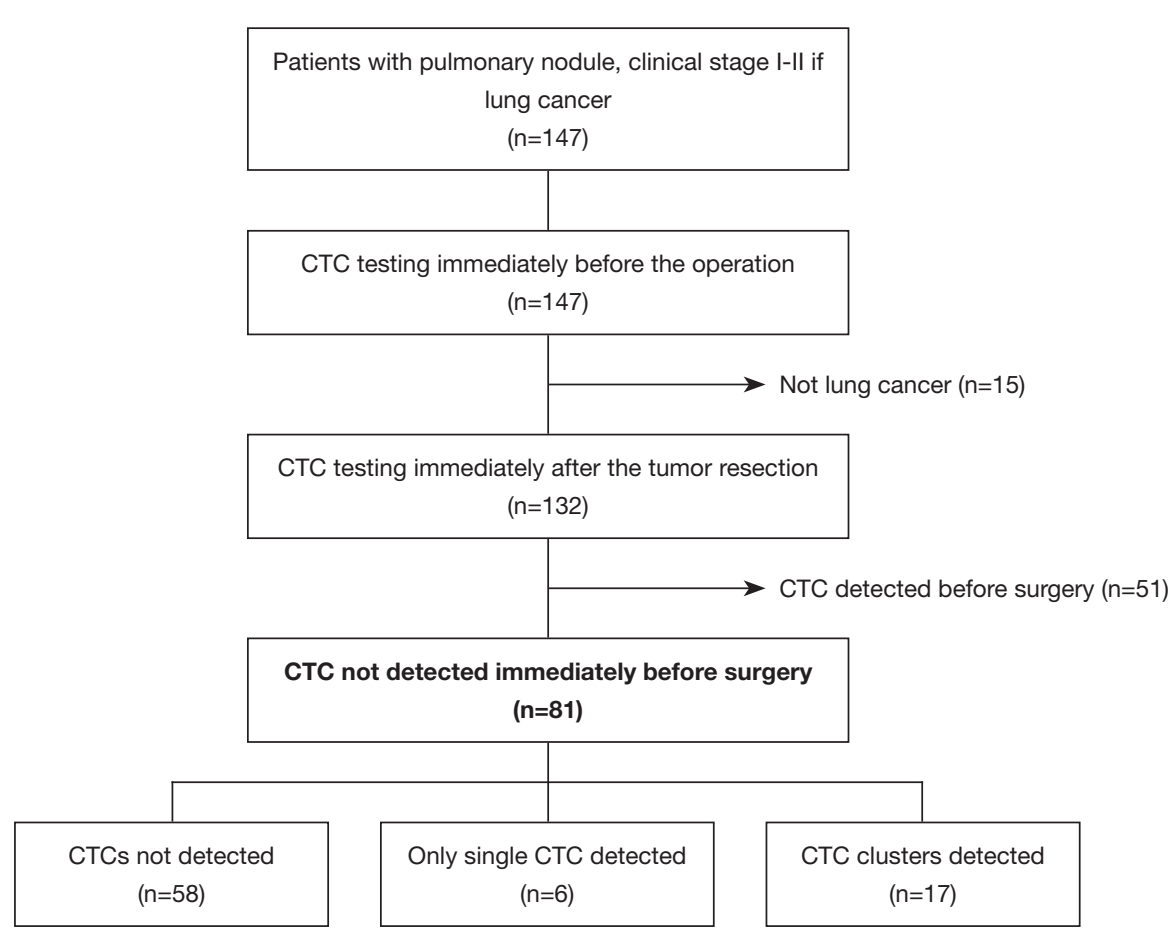

Figure 1 Study flowchart. CTCs, circulating tumor cells.

for lung cancer (4-7), we are not aware of any studies that evaluated postoperative CTC status and outcomes in cases where no CTCs were detected immediately before surgery. Therefore, the present study evaluated the clinical relevance of CTC detection immediately after lung cancer resection in cases without preoperatively detected CTCs. We present the following article in accordance with the STROBE reporting checklist (available at http://dx.doi.org/10.21037/ jtd-20-1636).

\section{Methods}

This retrospective study complied with the STROBE guidelines (8). The study included 81 lung cancer patients with negative preoperative results for CTCs and who completed postoperative testing for CTCs, as shown in Figure 1. The clinical relevance of postoperative CTC detection was evaluated based on the clinicopathological characteristics and recurrence patterns.

\section{Patient selection}

Between April 2014 and August 2018, 147 patients with pulmonary nodules (clinical stage I-II if lung cancer) that were detected using computed tomography (CT) underwent preoperative testing to detect CTCs at Hoshigaoka Medical Center or Nara Medical University Hospital. Among these cases, 132 cases were pathologically diagnosed as non-small cell lung cancer. However, the preoperative testing revealed CTCs in 51 cases, which were excluded. Thus, the present study included 81 cases without preoperative evidence of CTCs (Figure 1). The patients' characteristics are shown in Table 1.

\section{Surgical technique}

All operations were performed using video-assisted thoracic surgery (VATS) by one surgeon (N Sawabata). In cases involving lobectomy, the pulmonary vein was ligated first in 36 cases $(92.3 \%)$. In cases involving wedge resection, the distance from the tumor to the surgical margin was maximized without tumor release using ring-shaped forceps (P.N. CATCH, TKZ-F2640; Takasago, Tokyo, Japan) (9). Mediastinal lymph node removal was performed in cases with lobectomy, although lymph node sampling was performed if present in cases involving wedge resection. The surgeries were classified as pulmonary wedge resection in 30 cases, pulmonary wedge resection followed by 
Table 1 Patient characteristics

\begin{tabular}{|c|c|c|c|c|c|}
\hline Characteristics & All cases & \multicolumn{4}{|c|}{ Morphology of CTCs } \\
\hline Number of cases & 81 & $58(100.0)$ & $6(100.0)$ & $17(100.0)$ & \\
\hline CTC count & $2.42 \pm 3.64$ & 0 & $3.27 \pm 3.30$ & $5.80 \pm 3.70$ & $<0.01$ \\
\hline \multicolumn{6}{|l|}{ Sex } \\
\hline Male & 48 & $34(50.6)$ & $4(66.7)$ & $10(50.8)$ & \\
\hline Mean age (years) & $70.57 \pm 8.02$ & $70.90 \pm 7.58$ & $69.83 \pm 8.64$ & $69.71 \pm 5.92$ & 0.85 \\
\hline \multicolumn{6}{|l|}{ Lung cancer stage } \\
\hline Clinical & & & & & 0.82 \\
\hline Pathological & & & & & 0.06 \\
\hline I & 64 & $49(84.5)$ & $5(83.3)$ & $10(58.8)$ & \\
\hline II & 10 & $7(12.1)$ & $0(0)$ & $3(17.6)$ & \\
\hline III & 4 & $1(1.7)$ & $1(16.7)$ & $2(11.8)$ & \\
\hline IV & 3 & $1(1.7)$ & $0(0)$ & $2(11.8)$ & \\
\hline Pulmonary resection & & & & & 0.08 \\
\hline Wedge resection & 30 & $25(43.1)$ & $2(33.3)$ & $3(17.6)$ & \\
\hline Wedge + lobectomy ${ }^{*}$ & 12 & $11(19.0)$ & $0(0)$ & $1(5.9)$ & \\
\hline GGO + solid & 13 & $9(15.5)$ & $2(33.3)$ & $2(11.8)$ & \\
\hline Solid & 60 & $41(70.7)$ & $4(66.7)$ & $15(88.2)$ & \\
\hline Whole size $(\mathrm{cm})$ & $2.35 \pm 1.14$ & $2.25 \pm 1.18$ & $2.15 \pm 0.63$ & $2.75 \pm 1.12$ & 0.26 \\
\hline Solid size $(\mathrm{cm})$ & $2.01 \pm 1.33$ & $1.88 \pm 1.39$ & $2.00 \pm 0.77$ & $2.63 \pm 1.14$ & 0.13 \\
\hline \multicolumn{6}{|l|}{ Tumor markers } \\
\hline CEA (ng/mL) & $6.32 \pm 12.02$ & $5.51 \pm 9.95$ & $5.95 \pm 4.95$ & $9.18 \pm 18.72$ & 0.56 \\
\hline CYFRA (ng/mL) & $1.93 \pm 2.02$ & $2.07 \pm 2.29$ & $2.30 \pm 1.31$ & $1.36 \pm 0.73$ & 0.44 \\
\hline ProGRP $(p g / m L)$ & $56.84 \pm 20.36$ & $57.58 \pm 21.96$ & $69.10 \pm 14.90$ & $51.37 \pm 15.61$ & 0.29 \\
\hline SUVmax & $4.55 \pm 4.52$ & $4.04 \pm 4.77$ & $4.95 \pm 3.52$ & $6.10 \pm 3.71$ & 0.25 \\
\hline Gross size $(\mathrm{cm})$ & $2.27 \pm 1.09$ & $2.26 \pm 1.16$ & $2.43 \pm 1.04$ & $2.59 \pm 0.88$ & 0.35 \\
\hline
\end{tabular}

Table 1 (continued) 
Table 1 (continued)

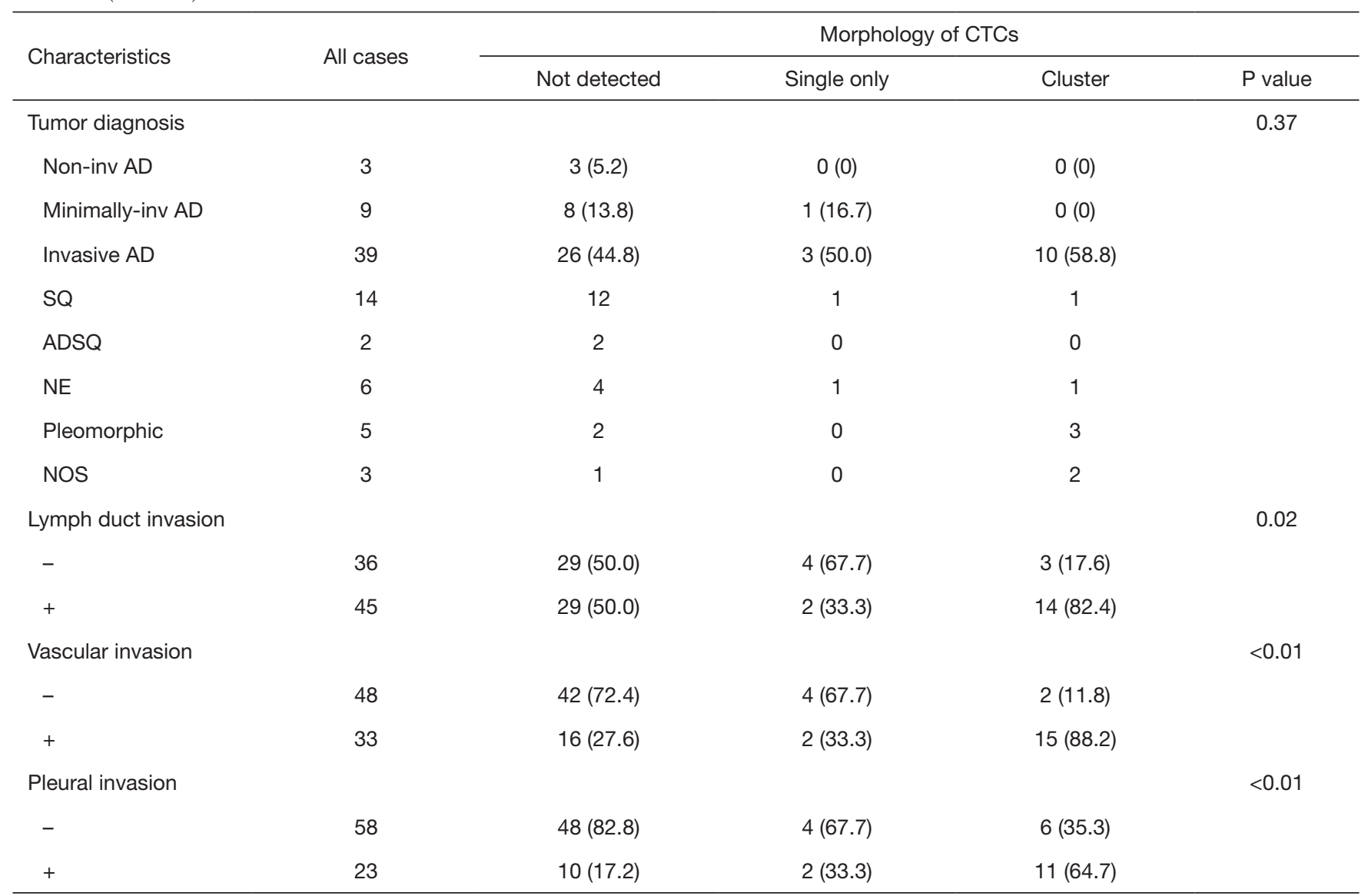

Data are reported as number (\%) or mean \pm standard deviation. *, wedge resection followed by lobectomy. AD, adenocarcinoma; $A D S Q$, adenosquamous cell carcinoma; CEA, carcinoembryonic antigen; CT, computed tomography; CTC, circulating tumor cells; CYFRA, cytokeratin 19 fragment; GGO, ground grass opacity; Minimally-inv, minimally invasive; NE, neuroendocrine cell carcinoma; Non-inv, noninvasive; ProGRP, progenitor of gastrin releasing peptide; SQ, squamous cell carcinoma; SUV, standard uptake value.

lobectomy in 12 cases, and lobectomy in 39 cases.

\section{Detection of CTCs}

Peripheral arterial blood $(3 \mathrm{~mL})$ was collected in the operating room immediately before surgery and placed in a tube with ethylenediaminetetraacetic acid. When the pathological examination confirmed the presence of lung cancer, we also obtained a postoperative blood sample for testing in the operating room at the completion of pulmonary resection. All samples were processed within 1 $h$ from the end of the operation. The presence of CTCs in the blood samples was evaluated using the ScreenCell ${ }^{\circledR}$ CTC selection kit, which uses a size-based selection method (10). To lyse the red blood cells before filtration, the blood samples were diluted in $4 \mathrm{~mL}$ of a buffer for fixing cells. After filtration of the fixed cells, the filter was washed with $1 \mathrm{~mL}$ of phosphate-buffered saline to remove the cellular debris. The extracted cells were then stained using hematoxylin and eosin and observed under a light microscope.

The presence of CTCs was determined based on a cytology atlas for CTCs from solid cancers (11). Suspicious cells were not considered CTCs for the present study. The CTC detection results were divided into three types based on the morphology findings: no CTCs were detected (Group N), only single CTCs were detected (Group S), and CTC clusters were detected (Group C). A "cluster" was defined as $\geq 4$ cells to minimize the contribution of collection- or preparation-related artifacts. All CTC evaluations were performed by a surgeon (N Sawabata) and the diagnoses were confirmed by a pathologist (T Ito). 
Table 2 Recurrence patterns according to morphology findings

\begin{tabular}{lcccc}
\hline \multirow{2}{*}{$\begin{array}{l}\text { Recurrence } \\
\text { pattern }\end{array}$} & Total & \multicolumn{2}{c}{ Morphology of CTCs } \\
\cline { 3 - 5 } & & Not detected $(\mathrm{n}=58)$ & Single only $(\mathrm{n}=6)$ & Cluster $(\mathrm{n}=17)$ \\
\hline No recurrence & $65(100.0)$ & $55(84.6)$ & $4(6.2)$ & $6(9.2)$ \\
Local & $2(100.0)$ & $0(0)$ & $1(50.0)$ & $1(50.0)$ \\
Regional & $7(100.0)$ & $3(42.9)$ & $0(0)$ & $4(57.1)$ \\
Distant & $7(100.0)$ & $0(0)$ & $1(14.3)$ & $6(85.7)$ \\
\hline
\end{tabular}

Data are reported as number (\%). Single only, only a single CTC was detected; Cluster, CTC clusters were detected. CTC, circulating tumor cell.

\section{Follow-up examinations}

All patients were followed at 1 - to 3-month intervals, which included physical and chest radiography examinations, as well as blood testing for tumor markers. The patients also underwent thoraco-abdominal CT scans that were generally performed at 6-month intervals. Mortality and recurrence data were collected by the primary physician (N Sawabata). The median follow-up period was 44 months (range, 18-68 months) and the last follow-up examination was during July 2019. Recurrence was classified as none, resection margin recurrence (local), ipsilateral intrathoracic recurrence (regional), or metastasis outside the ipsilateral intrathoracic cavity (distant).

\section{Statistical analysis}

The primary outcome was defined as the 2-year recurrencefree survival rate, which was evaluated based on KaplanMeier curves and the log-rank test. Cox proportional hazard models were used for the univariate and multivariate analyses. In addition, we investigated the associations between tumor-related factors and the morphological CTC classifications. Inter-group comparisons were performed using the $t$-test and Fisher's exact test, as appropriate, and differences were considered statistically significant at $\mathrm{P}$ values of $<0.05$. All analyses were performed using freely available "EZR" software, which is based on $R$ and $R$ commander (12).

\section{Ethical approval}

The study was conducted in accordance with the Declaration of Helsinki (as revised in 2013). This study's protocol was approved by the institutional review board of the Hoshigaoka Medical Center and the Nara Medical
University Hospital. Informed consent was obtained from all individual participants who were included in the study.

\section{Results}

\section{CTC morphology patterns}

Among 81 cases without preoperative evidence of CTCs (Figure 1), the morphology findings of postoperative CTC revealed one or more CTCs in 23 cases $(28.4 \%)$, which resulted in 58 cases $(71.6 \%)$ being assigned to Group N, 6 cases $(7.4 \%)$ being assigned to Group S, and 17 cases (21.0\%) being assigned to Group C. All patients with CTC clusters also had single CTCs that were detected. There were significant differences between the three groups in terms of lymph duct invasion, vascular invasion, and pleural invasion (Table 1).

\section{Prognosis analysis}

During the median follow-up period of 44 months, we identified 16 cases of recurrence, which included 7 cases of distant metastasis, 7 cases of local recurrence, and 2 cases of regional recurrence. We also identified 16 deaths, including 14 deaths that were related to lung cancer. Table 2 shows the recurrence types according to CTC morphology, which revealed that distant metastasis was more common in Group $\mathrm{C}$ than in the other groups. The 2-year recurrence-free survival rates were $94.6 \%$ for Group N, $62.5 \%$ for Group $\mathrm{S}$, and $52.9 \%$ for Group $\mathrm{C}(\mathrm{P}<0.01)$. In addition, the 2 -year overall survival rates were $96.5 \%$ for Group N, $80.0 \%$ for Group S, and $82.5 \%$ for Group C $(\mathrm{P}=0.02)$ (Figure 2). Table 3 shows the Cox proportional hazard ratios for recurrence-free survival, which were determined using the regression model. Relative to Group N, higher risks of recurrence were observed in Group S and Group 

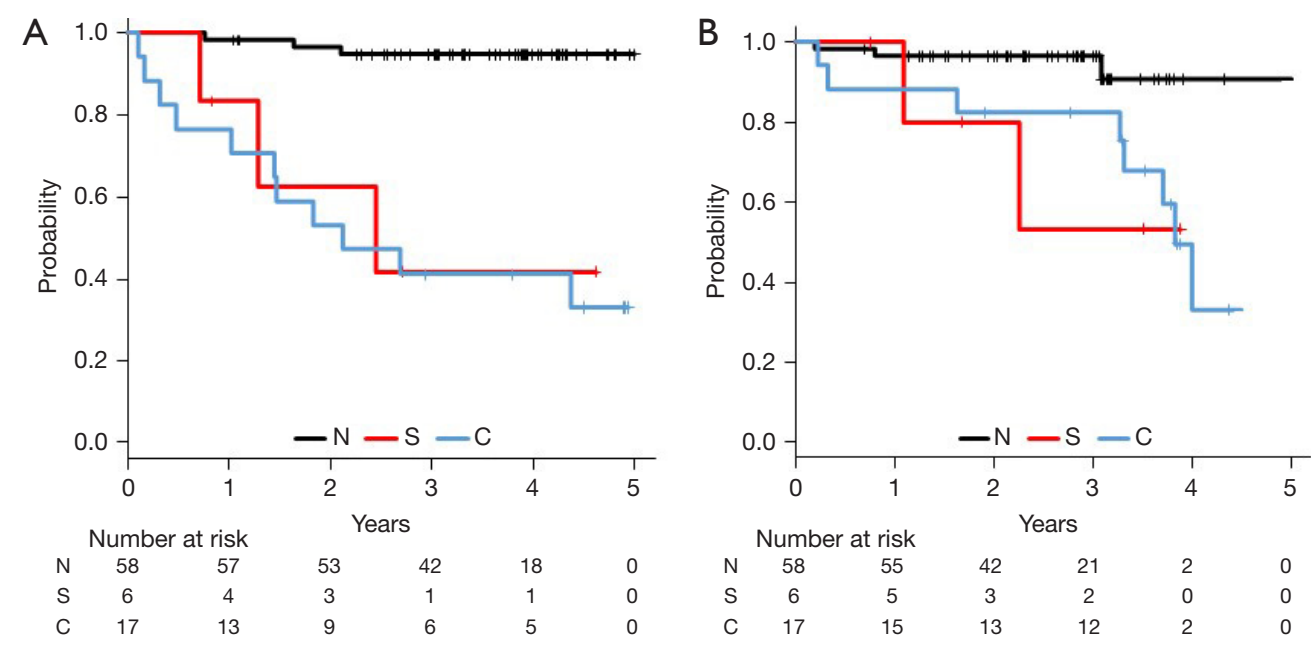

Figure 2 Survival according to circulating tumor cell morphology from immediately after the lung cancer resection. N, not detected; S, only single circulating tumor cell (CTC) detected; C, cluster CTCs were detected. The 2-year recurrence-free survival (RFS) rates were 94.6\% for Group N, 62.5\% for Group S, and 52.9\% for Group C ( $<<0.01)$ (A). The 2-year overall (OS) survival rates were 96.5\% for Group N, $80.0 \%$ for Group S, and $82.5 \%$ for Group C (P=0.02) (B).

Table 3 Cox proportional hazards regression model results for recurrence

\begin{tabular}{|c|c|c|c|c|c|c|}
\hline Variables & \multicolumn{3}{|c|}{ Univariable } & \multicolumn{3}{|c|}{ Multivariable } \\
\hline \multicolumn{7}{|c|}{ CTC morphology } \\
\hline Not detected & Ref. & - & - & Ref. & - & - \\
\hline Single only & 8.23 & $1.37-49.47$ & 0.02 & 14.79 & $1.86-117.10$ & 0.01 \\
\hline СTC count & 1.24 & $1.14-1.36$ & $<0.01$ & 0.925 & $0.76-1.13$ & 0.45 \\
\hline \multicolumn{7}{|l|}{ Sex } \\
\hline Female & Ref. & - & - & - & - & - \\
\hline Male & 0.89 & $0.33-2.4$ & 0.82 & - & - & - \\
\hline \multicolumn{7}{|c|}{ Lung cancer stage } \\
\hline \multicolumn{7}{|l|}{ Clinical } \\
\hline I & Ref & - & - & - & - & - \\
\hline II & 2.13 & $0.60-7.50$ & 0.24 & - & - & - \\
\hline \multicolumn{7}{|l|}{ Pathological } \\
\hline I & Ref. & - & - & Ref. & - & - \\
\hline ॥ & 3.53 & $0.88-14.11$ & 0.07 & 3.62 & $0.64-20.37$ & 0.14 \\
\hline III & 15.31 & $3.78-62.13$ & $<0.01$ & 13.65 & $1.54-120.90$ & 0.02 \\
\hline IV & 24.92 & $5.84-106.40$ & $<0.01$ & 16.75 & $2.93-95.73$ & $<0.01$ \\
\hline
\end{tabular}

Table 3 (continued) 
Table 3 (continued)

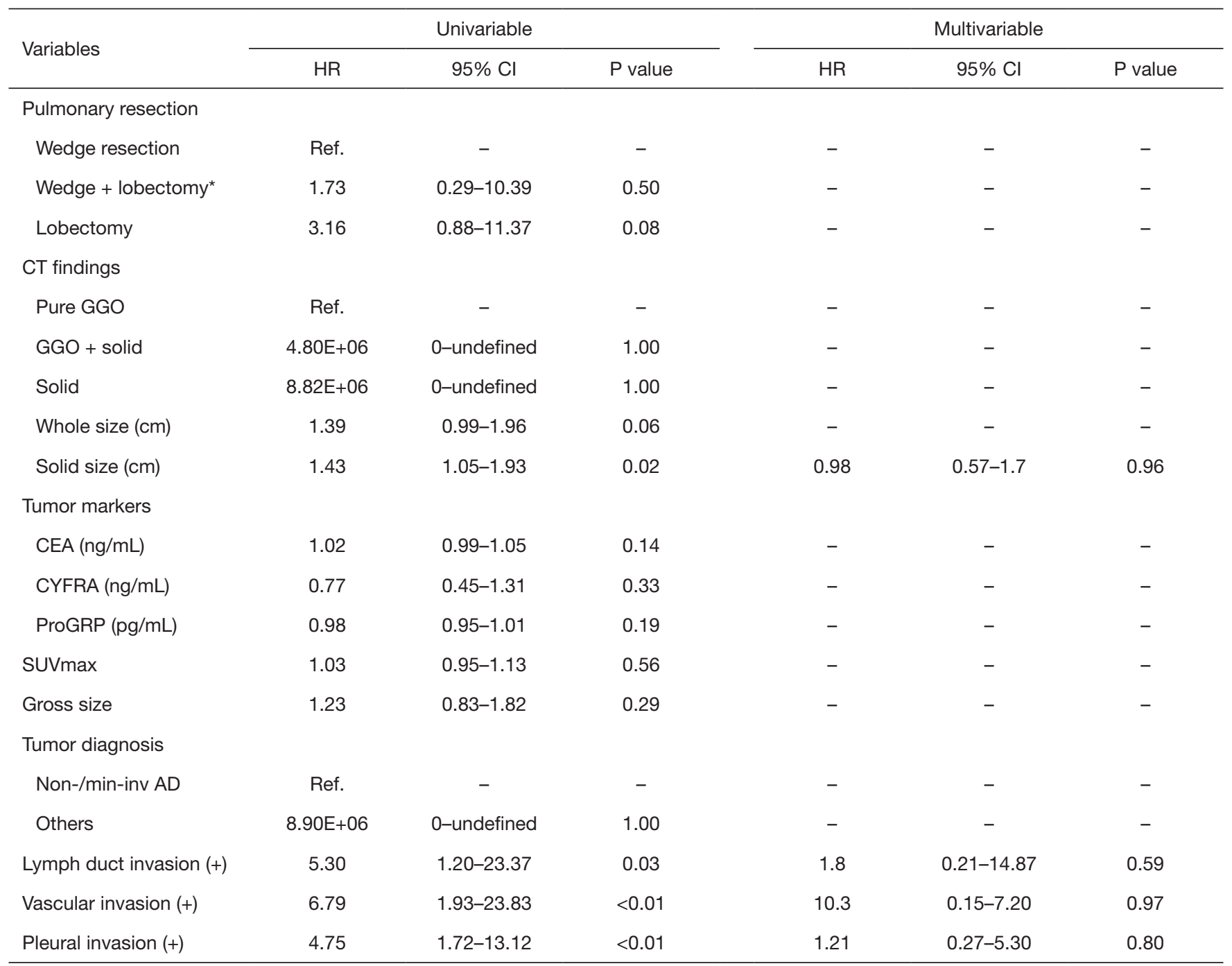

*, wedge resection followed by lobectomy. HR, hazard ratio; $\mathrm{Cl}$, confidence interval; Ref., reference; CTC, circulating tumor cells; $\mathrm{AD}$, adenocarcinoma; CT, computed tomography; GGO, ground grass opacity; CEA, carcinoembryonic antigen; CYFRA, cytokeratin 19 fragment; ProGRP, progenitor of gastrin releasing peptide; SUV, standard uptake value; Non-/min-inv, non-invasive or minimally invasive.

C. Significant differences in recurrence were observed according to postoperative CTC detection and pathological stage. The morphological CTC classifications were also found to independently predict recurrence.

Some reports regarding lung cancer cases have described CTC detection after surgical manipulation, although the clinical relevance of these postoperatively detected CTCs remains controversial. Before the current morphological detection method became ubiquitously available, CTC shedding after surgical manipulation was identified using a real-time polymerase chain reaction method
(13-15). Yamashita et al. also described the detection of CTCs in peripheral blood by targeting the mRNA for carcinoembryonic antigen (CEA), which revealed that, among patients without preoperative evidence of CTCs, approximately $30 \%$ of patients had postoperatively detected CTCs (14). Yao et al. also reported that CTCs were surgically shed in the pulmonary vein using fluorescenceactivated cell sorting that targeted the epithelial cell adhesion molecule (EpCAM) (15). In 2007, Sawabata et al. reported the morphological evaluation of CTCs using the CellSearch ${ }^{\circledR}$ system after surgery for lung cancer (16). 
That system can visualize a single CTC and their findings revealed postoperative CTCs in approximately $25 \%$ of patients who did not exhibit preoperative CTCs. Furthermore, Matsutani et al. evaluated CTC shedding after pulmonary resection in a multi-center prospective study using a micropore film size-based selection method $\left(\right.$ ScreenCell $\left.{ }^{\circledR}\right)$ (17). Hashimoto et al. also used the CellSearch ${ }^{\circledR}$ method to determine that a postoperatively increased CTC count was a significant predictor of distant metastasis (18). Moreover, despite a small sample size, Sawabata et al. used the ScreenCell ${ }^{\circledR}$ method to determine that both preoperative and postoperative detection of CTC clusters were significant predictors of early recurrence (19). A novel finding from the present study is that distant metastasis was very common in cases with CTC clusters that were detected immediately after the resection, which suggests that CTC clusters in this setting may predict the development of distant metastasis. However, an issue with immunostaining-based CTC detection is the fact that epithelial markers may not be detectable on CTC clusters, which suggests that it is still important to perform morphological CTC detection.

Management of the pulmonary vasculature before resection of lung cancer can be considered a type of NTIT, which we routinely use in cases involving lobectomy. Song et al. used real-time PCR to determine that a lower CTC count was observed for patients who underwent a vein-first ligation technique, relative to patients who underwent an artery-first ligation technique (20). Wei et al. also recently reported that the postoperative CTC count was lower for the vein-first technique, based on an antigen-positive selection method (21), and that the vein-first technique was associated with better survival outcomes. There are additional reports that vein-first lobectomy is associated with significantly better survival outcomes (21-23), although other studies have failed to detect a significant difference in survival between the vein-first and artery-first techniques (24-26). The presence of postoperative CTCs appears to be a more sensitive predictor of recurrence (27), and the present study's findings suggest that surgical manipulation can lead to seeding of CTCs, which become detectable after surgery and presumably contribute to recurrence and distant metastasis. It seems logical that postoperative single CTC detection would predict recurrence, although preoperative single CTC detection does not seem to be related to postoperative recurrence (28).

The present study has several limitations. First, the small sample size from only two centers and the retrospective design highlight the potential risks of bias. Second, the patients underwent various forms of surgery, including wedge resection, wedge resection followed by lobectomy, and lobectomy alone, although the surgical technique was not a significant factor in the regression analysis. Nevertheless, our wedge resection technique without tumor release using ring-shaped forceps has a low potential for releasing CTCs (9). We also only considered cases without preoperative evidence of CTCs, which is an ideal group to investigate the relevance of CTC detection after surgical manipulation. However, we performed the CTC detection using 3-mL blood samples, which are relatively small, and the results might be more accurate if larger blood samples were used. In addition, the generalizability of our findings needs be established via other studies in the same setting.

\section{Conclusions}

The present study revealed that, among patients treated for non-small cell lung cancer at our center, CTCs could be detected immediately after surgery, and that these postoperatively detected CTCs were an independent predictor of recurrence.

\section{Acknowledgments}

The authors thank Dr. Ikuko Torii (Department of Pathology, Hoshigaoka Medical Center) for her contributions to the cytological-pathological diagnoses. The authors also thank Editage for English language editing. These findings were presented at the $56^{\text {th }}$ annual meeting of the Society of Thoracic Surgeons (January $26^{\text {th }}, 2020$, New Orleans, USA).

Funding: This study was funded by a Grant-in-Aid for Scientific Research (B) from the Japan Ministry of Education, Science, Sports and Culture (25293301) and by the Japanese Respiratory Foundation (2019).

\section{Footnote}

Reporting Checklist: The authors have completed the STROBE reporting checklist. Available at http://dx.doi. org/10.21037/jtd-20-1636

Data Sharing Statement: Available at http://dx.doi. org/10.21037/jtd-20-1636

Peer Review File: Available at http://dx.doi.org/10.21037/jtd- 
$20-1636$

Conflicts of Interest: All authors have completed the ICMJE uniform disclosure form (available at http://dx.doi. org/10.21037/jtd-20-1636). The authors have no conflicts of interest to declare.

Ethical Statement: The authors are accountable for all aspects of the work in ensuring that questions related to the accuracy or integrity of any part of the work are appropriately investigated and resolved. The study was conducted in accordance with the Declaration of Helsinki (as revised in 2013). This study's protocol was approved by the institutional review board of the Hoshigaoka Medical Center (No. 1412) and the Nara Medical University Hospital (No. 1718). Informed consent was obtained from all individual participants who were included in the study.

Open Access Statement: This is an Open Access article distributed in accordance with the Creative Commons Attribution-NonCommercial-NoDerivs 4.0 International License (CC BY-NC-ND 4.0), which permits the noncommercial replication and distribution of the article with the strict proviso that no changes or edits are made and the original work is properly cited (including links to both the formal publication through the relevant DOI and the license). See: https://creativecommons.org/licenses/by-nc-nd/4.0/.

\section{References}

1. Bottos A, Hynes NE. Cancer: Staying together on the road to metastasis. Nature 2014;514:309-10.

2. Turnbull RB Jr, Kyle K, Watson FR, et al. Cancer of the colon: the influence of the no-touch isolation technic on survival rates. Ann Surg 1967;166:420-7.

3. Takii Y, Shimada Y, Moriya Y, et al. A randomized controlled trial of the conventional technique versus the no-touch isolation technique for primary tumor resection in patients with colorectal cancer: Japan Clinical Oncology Group Study JCOG1006. Jpn J Clin Oncol 2014;44:97-100.

4. Chudasama D, Barr J, Beeson J, et al. Detection of Circulating Tumour Cells and Survival of Patients with Non-small Cell Lung Cancer. Anticancer Res 2017;37:169-73.

5. Hofman V, Bonnetaud C, Ilie MI, et al. Preoperative circulating tumor cell detection using the isolation by size of epithelial tumor cell method for patients with lung cancer is a new prognostic biomarker. Clin Cancer Res 2011;17:827-35.

6. Bayarri-Lara C, Ortega FG, Cueto Ladrón de Guevara A, et al. Circulating Tumor Cells Identify Early Recurrence in Patients with Non-Small Cell Lung Cancer Undergoing Radical Resection. PLoS One 2016;11:e0148659.

7. Dandachi N, Tiran V, Lindenmann J, et al. Frequency and clinical impact of preoperative circulating tumor cells in resectable non-metastatic lung adenocarcinomas. Lung Cancer 2017;113:152-7.

8. von Elm E, Altman D G, Egger M, et al. The Strengthening the Reporting of Observational Studies in Epidemiology (STROBE) statement: guidelines for reporting observational studies. Ann Intern Med 2007;147:573-7.

9. Sawabata N, Hyakutaka T, Kawaguchi T, et al. A notouch technique for pulmonary wedge resection of lung cancer. Gen Thorac Cardiovasc Surg 2018;66:161-7.

10. Desitter I, Guerrouahen BS, Benali-Furet N, et al. A new device for rapid isolation by size and characterization of rare circulating tumor cells. Anticancer Res 2011;31:427-41.

11. Wechsler J. Circulating tumor cells. In: Wechsler J, editor. Circulating tumor cells from solid cancers. 1st ed. Paris: Sauramps Medical, 2015:44-50.

12. Kanda Y. Investigation of the freely available easy-touse software 'EZR' for medical statistics. Bone Marrow Transplant. 2013;48:452-8.

13. Kurusu, Y, Yamashita, J, Ogawa, M. Detection of circulating tumor cells by reverse transcriptase-polymerase chain reaction in patients with resectable non-small-cell lung cancer. Surgery 1999;126;820-6.

14. Yamashita JI, Kurusu Y, Fujino N, et al. Detection of circulating tumor cells in patients with non-small cell lung cancer undergoing lobectomy by video-assisted thoracic surgery: a potential hazard for intraoperative hematogenous tumor cell dissemination. J Thorac Cardiovasc Surg 2000;119:899-905.

15. Yao X, Williamson C, Adalsteinsson VA, et al. Tumor cells are dislodged into the pulmonary vein during lobectomy. J Thorac Cardiovasc Surg 2014;148:3224-31.

16. Sawabata N, Okumura M, Utsumi T, et al. Circulating tumor cells in peripheral blood caused by surgical manipulation of non-small-cell lung cancer: pilot study using an immunocytology method. Gen Thorac Cardiovasc Surg 2007;5 5:189-92.

17. Matsutani N, Sawabata N, Yamaguchi M, et al. Does lung cancer surgery cause circulating tumor cells?-A multicenter, prospective study. J Thorac Dis 
2017;9:2419-26.

18. Hashimoto M, Tanaka F, Yoneda K, et al. Positive correlation between postoperative tumor recurrence and changes in circulating tumor cell counts in pulmonary venous blood (pvCTC) during surgical manipulation in non-small cell lung cancer. J Thorac Dis 2018;10:298-306.

19. Sawabata N, Funaki S, Hyakutake T, et al. Perioperative circulating tumor cells in surgical patients with non-small cell lung cancer: does surgical manipulation dislodge cancer cells thus allowing them to pass into the peripheral blood? Surg Today 2016;46:1402-9.

20. Song PP, Zhang W, Zhang B, et al. Effects of different sequences of pulmonary artery and vein ligations during pulmonary lobectomy on blood micrometastasis of nonsmall cell lung cancer. Oncol Lett 2013;5:463-8.

21. Wei S, Guo C, He J, et al. Effect of vein-first vs artery-first surgical technique on circulating tumor cells and survival in patients with non-small cell lung cancer: a randomized clinical trial and registry-based propensity score matching analysis. JAMA Surg 2019;154:e190972.

22. Ge MJ, Shi D, Wu QC, et al. Observation of circulating tumour cells in patients with non-small cell lung cancer by real-time fluorescent quantitative reverse transcriptasepolymerase chain reaction in peroperative period. J Cancer Res Clin Oncol 2006;132:248-56.

23. Sumitomo R, Fukui T, Marumo S, et al. Effects of vessel

Cite this article as: Sawabata N, Nakamura T, Kawaguchi T, Watanabe T, Ouji NS, Ito T, Taniguchi S. Circulating tumor cells detected only after surgery for non-small cell lung cancer: is it a predictor of recurrence? J Thorac Dis 2020;12(9):46234632. doi: $10.21037 /$ jtd-20-1636 interruption sequence during thoracoscopic lobectomy for non-small cell lung cancer. Gen Thorac Cardiovasc Surg 2018;66:464-70.

24. Refaely Y, Sadetzki S, Chetrit A, et al. The sequence of vessel interruption during lobectomy for non-small cell lung cancer: is it indeed important? J Thorac Cardiovasc Surg 2003;125:1313-20.

25. Kozak A, Alchimowicz J, Safranow K, et al. The impact of the sequence of pulmonary vessel ligation during anatomic resection for lung cancer on long-term survival--a prospective randomized trial. Adv Med Sci 2013;58:156-63.

26. Hashimoto M, Tanaka F, Yoneda K, et al. Significant increase in circulating tumour cells in pulmonary venous blood during surgical manipulation in patients with primary lung cancer. Interact Cardiovasc Thorac Surg 2014;18:775-83.

27. Hofman V, Ilie MI, Long E, et al. Detection of circulating tumor cells as a prognostic factor in patients undergoing radical surgery for non-small-cell lung carcinoma: comparison of the efficacy of the CellSearch Assay ${ }^{\mathrm{TM}}$ and the isolation by size of epithelial tumor cell method. Int J Cancer 2011;129:1651-60.

28. Sawabata N, Susaki Y, Nakamura T, et al. Cluster circulating tumor cells in surgical cases of lung cancer. Gen Thorac Cardiovasc Surg 2020;68:975-83. 